\title{
A dialética transcendental entre as palavras e as coisas
}

\author{
Pedro Paulo Garrido Pimenta \\ Universidade de São Paulo
}

resumo 0 objetivo é investigar se a Dialética transcendental de Kant, ao se deter sobre as condições que dão origem ao conflito da razão consigo mesma, não oferece ainda uma reflexão acerca da regulação transcendental do discurso e da linguagem filosófica.

palavras-chave Razão; Dialética Transcendental; Linguagem; Discurso

O mote de nossa exposição é um texto do crítico inglês Thomas De Quincey, uma passagem de uma das cartas redigidas para o benefício de "um jovem, cuja educação foi negligenciada”. O título da CartaV é "Da recepção de Kant na Inglaterra". Ali, podemos ler o seguinte:

A terminologia de Kant não se restringe a atribuir um novo nome a idéias já existentes na consciência universal, mas é em parte a aquisição de novos territórios para o entendimento, em parte uma melhor regulação de seu velho território. Essa regulação ou é negativa e consiste em delimitar com mais precisão a fronteira de concepções até então definidas de maneira imperfeita, ou é positiva e consiste em substituir por nomes que expressam relações e subordinações do objeto (termini organici) os nomes convencionais e acidentais, que não expressam tais relações (termini bruti). (DE QUINCEY 1897, pp. 76 - 77)

De Quincey adverte o seu interlocutor para que não confunda na leitura de Kant, como amiúde na Inglaterra daqueles tempos, o significado de termos semelhantes mas tão distintos como "transcendente" e "transcen-

Recebido em 3 de outubro de 2006. Aceito em 20 de dezembro de 2006.

doispontos, Curitiba, São Carlos, vol. 4, n. 1, p. 27-46, abril, 2007 


\section{8}

dental", e mesmo o deste "transcendental" moderno com aquele da filosofia escolástica. De nossa parte, observaremos que essa observação perspicaz tem o seu reverso: pois nem sempre é o caso de Kant substituir "termos brutos", apropriados da linguagem corrente ou herdados de uma tradição longínqua, por "termos orgânicos”, mais técnicos e precisos. Por vezes, ocorre o inevitável: as palavras faltam ao filósofo, as coisas precisam ser nomeadas, e tudo o que ele encontra são termos capciosos e vagos. É então que o exercício crítico da filosofia se condensa em glosa: de idéias e palavras, de sentenças e textos.

Há um paradoxo na natureza das nossas idéias, segundo a Dialética transcendental. Por definição, idéias da razão dizem respeito ao "incondicionado", o "conceito transcendental da razão" não sendo mais que "o conceito da totalidade das condições relativamente a um condicionado dado” (KANT 1987, B 379). Os motivos dessa constatação são oferecidos por Kant num percurso que mostra como o uso meramente lógico da razão nas inferências do entendimento engendra a forma do raciocínio sofistico que levará a faculdade de idéias a se tomar a si mesma por faculdade de conceitos, e a fundar, com base nesse extravio, uma especulação que tem em vista algo mais que dados da experiência sensível (KANT 1987, B $360-61)$.

Se o uso lógico-transcendental da razão tem validade objetiva para efeito de descrição dos fenômenos é porque se refere exclusivamente a dados sensíveis. Os termos da transição do uso lógico ao uso transcendental da razão devem ser cuidadosamente estipulados para que não se confunda a validade formal de uma categoria com a intelecção de um conteúdo que estaria para além de toda experiência. Não é porque raciocino sobre alguma coisa que tenho uma intuição dela. No caso da razão, ocorre o contrário, e o filósofo deve aprender a pensar sem querer intuir. Essa situação parece justificadamente desconcertante. Mas é preciso não esquecer que uma das novidades da primeira Crítica consiste na problematização de uma "aparência transcendental" a partir de uma "aparência lógica” no uso puro da razão. ${ }^{1}$

doispontos, Curitiba, São Carlos, vol. 4, n. 1, p. 27-46, abril, 2007 
Como explica o próprio Kant, o uso dialético da razão não é caracterizado por sofismas voluntários, pela má intenção do argüidor que quer ludibriar o interlocutor. Sofismas são recursos da ars oratoria, "arte de servir-se das fraquezas dos homens para seus propósitos" que "não é digna de nenhum apreço (Achtung)" (KANT 1992, B 217). Trata-se de um recurso técnico de argumentação inteiramente contingente: eu posso ou não recorrer a ele, e mais, posso fazê-lo de maneira legítima, desde que utilize a retórica de maneira adequada, como manancial de recursos da "eloqüência e do bem-falar" (Bredheit und Wohlredenheit) que servem para ressaltar pontos de razão num raciocínio ou para intensificar o efeito deles, contribuindo para esclarecê-lo (KANT 1992, B 217). Essa concepção de retórica permite-nos compreender qual seria para Kant o estatuto da dialética enquanto maneira do discurso filosófico: pois tratase de algo estruturalmente diferente da arte retórica.

Para delimitar o lugar próprio da dialética é preciso entender o papel desempenhado pela lógica na elaboração do conhecimento. A lógica "expõe as regras gerais e necessárias do entendimento", regras essas que devem incluir "critérios de verdade" (KANT 1987, B 84). O "critério puramente lógico da verdade" diz respeito à "concordância de um conhecimento com as leis gerais e formais do entendimento e da razão", e é nessa medida "uma condição negativa de toda a verdade" (KANT 1987, B 84). E precisamente nesse mérito indispensável reside a limitação de seu alcance, dado que as regras lógicas não são suficientes para nos alertar do "erro que incide não sobre a forma, mas sobre o conteúdo": falta-nos aqui uma "pedra de toque" (Probierstein) da verdade, a coerência lógica do conhecimento é insuficiente para decidir acerca da "verdade material (objetiva)" do conhecimento (KANT 1987, B 84 - 85).

Kant esclarece que "o entendimento em suas ações está ligado a regras" particulares "que podemos investigar"; o conjunto dessas regras recebe a denominação de "lógica" enquanto disciplina acadêmica passível de ser ensinada e aprendida. O "entendimento é a fonte e a faculdade de pensar regras em geral", e o seu interesse está sobretudo em encontrálas para "submeter a regras as representações dos sentidos". Para "satisfazer-se" disso, procede entretanto segundo regras; e cabe saber quais são essas regras e de onde elas vêm (KANT 1992, A 2 - 3). É claro portanto que, se a exposição sistemática e ordenada de regras constitui o cânon da

doispontos, Curitiba, São Carlos, vol. 4, n. 1, p. 27-46, abril, 2007 
lógica formal, que serve para todo e qualquer ato da mente, se encontra no discurso cotidiano, articulado por seres racionais, algo como uma lógica espontânea. A noção da lógica como disciplina do raciocínio humano é oferecida por Kant a partir de uma analogia:

O exercício de nossos poderes também acontece segundo certas regras que seguimos, a princípio, sem consciência delas, até chegarmos aos poucos ao conhecimento delas mediante diversas tentativas e um prolongado uso de nossos poderes, tornando-as por fim tão familiares que muito esforço nos custa pensá-las in abstracto. Assim, por exemplo, a gramática geral é a forma de uma língua em geral. Mas também falamos sem conhecer a gramática; e quem fala sem conhecê-la tem realmente uma gramática e fala segundo regras das quais, porém, não está consciente. (KANT 1992, A 2)

A comparação com a "gramática geral", disciplina que ocupava no currículo universitário o plano mais elevado, ao lado da própria lógica e da retórica, é interessante e permite entender um ponto importante. $\mathrm{O}$ uso da lógica é inerente a todo pensamento, não importa se consciente ou não, se refletido ou irrefletido. A lógica é um dado tão "natural" quanto o talento de julgar, ao qual ela parece estar intimamente vinculada. (KANT 1987, B 171 - 72) A lógica versa sobre a forma do pensamento em raciocínios; e se a espécie de raciocínio envolve dados intuitivos e é elaborada pelo entendimento, faculdade de conhecimento, então a lógica se definirá como uma "ciência de regras", e tais que

podem ser discernidas a priori, isto é, independentemente de toda experiência, porque elas contêm, sem distinção dos objetos, as meras condições do uso do entendimento em geral, quer puro, quer empírico. (KANT 1992, A 4)

A lógica inclui assim, numa acepção transcendental, a regra segundo a qual se manifesta o discernimento da faculdade-de-julgar, de tal maneira que a objetividade parece estar pressuposta em cada ato de síntese: é um dado a priori. É o que explica Kant, explorando a analogia entre a lógica e a gramática:

Podemos fazer uma idéia da possibilidade dessa ciência [a lógica], exatamente como de uma gramática geral, que nada mais contém 
senão a mera forma da língua, sem as palavras, que pertencem à matéria da língua. (KANT 1992, A 4)

A língua se fala sem nenhum conhecimento de gramática, assim como raciocinamos e julgamos mesmo sem o conhecimento de regras. Quem não conhece uma língua pode ser instruído nela, mas quem não sabe como falar permanecerá mudo. O pressuposto de uma lógica natural a ser sistematizada num conjunto de regras explica porque, mesmo quando sistematizamos a lógica numa doutrina, somos dados a deixar de lado uma reflexão, entretanto necessária, acerca dos princípios e do alcance desse corpus. Reconhecemos no sistema da lógica no qual somos instruídos as regras que antes utilizávamos mas das quais não estávamos cientes. É como se a naturalidade do uso do entendimento nos desincumbisse de uma investigação que leve a sério a possibilidade de um mau uso de suas regras. O raciocínio correto simplesmente não se questiona acerca da adequação entre a forma do pensar a matéria a ser pensada. Em suma, do fato de que raciocinamos corretamente não decorre que tenhamos adquirido algo que não pode ser adquirido, o talento especial do discernimento, que julga da pertinência da aplicação deste conceito a esta intuição, e, num sentido mais lato, de um conceito a um objeto do qual nós não temos uma intuição. ${ }^{2}$

Vemos assim que a lógica, a exemplo da própria retórica, é uma "arte especiosa" (scheinbaren Kunst) cuja posse nos sugere, tanto quanto a daquela outra arte, algumas “tentações” (Verleitenden), quiçá irresistíveis. Sua precisão e elegância, mas principalmente a eficácia que ela empresta aos argumentos mais dificeis tornam a lógica um instrumento praticamente irresistível para o filósofo. Talvez por isso tome-se esse "cânon" do julgar por um "organon", como se as condições formais de concordância do conhecimento com o entendimento não fossem "indiferentes em relação aos objetos” (KANT 1987, B 86); mas

a lógica, verdadeiramente, deveria ser apenas o cânon para ajuizar do uso empírico (do entendimento), e é abuso dar-lhe o valor de organon para o uso geral e ilimitado, e constitui atrevimento julgar, afirmar e decidir sinteticamente sobre objetos em geral, utilizando somente o entendimento puro. (KANT 1987, B 88)

doispontos, Curitiba, São Carlos, vol. 4, n. 1, p. 27-46, abril, 2007 
É preciso distinguir a lógica formal, mera disciplina escolar, cujo estudo é sem dúvida indispensável para a boa filosofia, da lógica transcendental, que estuda esta curiosa situação: um raciocínio perfeitamente correto não apenas não é a garantia de um conhecimento certo como ainda estende um véu diante de nós que nos separa de um tal conhecimento. Não por outra razão dirá Kant que o nome próprio da lógica em sua acepção propriamente transcendental é "crítica da aparência dialética", não como uma mera "arte", mas como "crítica do entendimento e da razão". Ora, como é amplamente sabido no século XVIII, toda arte deve conduzir-se de acordo com as regras que lhe cabem, sem as quais ela não poderia se realizar enquanto tal. $\mathrm{O}$ estabelecimento de regras cabe ao crítico. A filosofia crítica inclui, portanto, uma investigação aprofundada dos meandros pelos quais a lógica formal dá ensejo a uma lógica da aparência. Isso sugere que os abusos da lógica pelos metafísicos são algo mais, em sua origem, que um recurso para "embelezar proposições vazias". Os ares de "profundidade" daqueles que a pervertem deliberadamente não passam do resultado final de um processo que se enraíza na razão humana. A deturpação de caráter que aproxima o lógico do orador não é uma falta moral, mas indica algo da natureza universal e imutável da razão, como confirma o testemunho dos diferentes sistemas filosóficos.

A razão não tem conceitos, mas toma-os do entendimento; nenhum conceito do entendimento pode se adequar, entretanto, à exigência de conteúdo da razão - "isto é, um conceito que possa ser mostrado e que seja suscetível de se tornar objeto de uma intuição numa experiência possível" -, e tudo o que podemos conceber de um objeto sem intuição correspondente é um "conceito problemático" (KANT 1987, B 396 - 97). É preciso sublinhar esta última expressão: einen problematische Begriff. O que ela indica é que o conceito de um objeto impossível de ser conhecido pode ser um conceito real: "a realidade (Realität) transcendental (subjetiva) dos conceitos puros da razão funda-se, pelo menos, em que, por um raciocínio necessário, somos levados a tais idéias" (KANT 1987, B 397). Sem ser dado na experiência (sem ser efetivo: Wirklich), o conceito transcendental da razão é subjetivamente necessário, isto é, decorre da forma lógica comum a todo e qualquer raciocínio.

doispontos, Curitiba, São Carlos, vol. 4, n. 1, p. 27-46, abril, 2007 
A promiscuidade entre o uso lógico da razão e a instância transcendental dos princípios dessa faculdade constrange-nos a uma constatação problemática:

Deverá então haver raciocínios que não contenham premissas empíricas

e, mediante os quais, de algo que conhecemos inferimos alguma outra coisa, de que não possuímos qualquer conceito, mas a que, todavia, por uma aparência inevitável, atribuímos realidade objetiva (objektive

Realität) (KANT 1987, B 397).

O jogo se dá entre a realidade subjetiva e a realidade objetiva do conceito: esta é um atributo (gegebenheit) indissociável, aquela é circunstancial. Quando se perde a referência sensível, a validade do conceito se torna meramente subjetiva, e só é lícito lhe atribuir realidade subjetiva na medida em que reconhecemos que ele é problemático, advindo de uma inferência que parte de um dado sensível mas almeja um supra-sensível (Übersinnliches). A legalidade desse arranjo depende de o filósofo estar ciente de que se trata de uma armação puramente conceitual - diríamos já: raciocinante - que diz mais da natureza da faculdade da razão do que da natureza das coisas que se tem em vista numa instância como o suprasensível. A atribuição de objetividade a essa Realität só poderia ser ilusória, pois a objetividade conceitual precisa de algo mais que coerência lógica: requer uma Wirklichkeit, a posição de um objeto sensível na forma pura da intuição. Daí a importante diferença, demarcada por Kant em inúmeras passagens de sua obra, entre "objetos em geral” (Objekte), da razão, e "objetos" (Gegenstände), do entendimento. ${ }^{3}$

As considerações que não levam em conta essa distinção e atribuem Wirklichkeit ao que só tem Realität são "quanto aos resultados, sofismas (vernünftelnde), embora quanto à sua origem lhes possa competir o nome de raciocínios" (KANT 1987, B 397). Essa ressalva é importante, pois se o sofisma não é um raciocínio, mas sim uma artimanha, o que temos aqui é algo inteiramente diferente, raciocínios que degeneram em sofismas. Sua origem está "na natureza da razão" (die aus der Natur der Vernunft entsprungen sind), são "sofisticações" (Sophistikationen) das quais nenhum homem está livre, por mais sábio que seja (KANT 1987, B 397). Contra o ardil retórico, que toca a minha paixão, posso recorrer à frieza da razão: mas, em se tratando de raciocínios destinados a degenerar em sofisma, o 
que está em jogo não é o artifício de um argumento especioso, mas a natureza da razão em geral. O máximo que pode o nosso "esforço" é evitar o "erro" (Irrtum), mas não a "aparência" (Schein). ${ }^{4}$ Essa diferença é fundamental: explica porque a solidez do edifício lógico, longe de ser suficiente para combater a ilusão, é posta a seu serviço, reforçando a aparência de uma efetividade ali onde se encontra simples realidade. A Dialética transcendental não é uma consideração separada da Analítica, da qual poderíamos lançar mão quando obtivéssemos uma lógica mais perfeita que a de Kant: é um corretivo das mazelas decorrentes da extrema eficácia do uso lógico da razão. O filósofo crítico a concebe como um episódio cuja ocorrência não pode ser evitada em virtude da mera exposição: as páginas da Dialética tem validade irrevogável, são um alerta permanente contra o uso sofístico da razão. ${ }^{5}$

Expõe-se na Dialética transcendental a "relação natural" (naturlische Beziehung) que há entre o uso lógico e o uso transcendental do conhecimento, "tanto em raciocínios como em juízos" (KANT 1987, B 390). Kant fala em três "espécies" (Arten) de "raciocínios dialéticos", são três os raciocínios pelos quais a razão se descola do entendimento na síntese lógica para tornar-se uma faculdade autônoma, com princípios próprios, na consecução de uma síntese transcendental. A razão busca, nesse movimento, ascender à síntese incondicionada (unbedingte) que é logicamente exigida como condição das sínteses condicionadas (bedingte) do entendimento (KANT 1987, B 390). É na referência necessária do condicionado a um incondicionado que se gesta a inevitável contradição entre o entendimento e a razão. ${ }^{6}$

Como explica Kant, as relações que se encontram em nossas "representações" (Vorstellungen) se restringem a duas: ao sujeito consigo mesmo, e à relação deste com objetos - quer sejam tomados como fenômenos, objetos dados na representação, quer sejam tomados como coisas em si, objetos indeterminados, "do pensamento em geral". Depreende-se dessa restrição de natureza lógica a forma própria das idéias da razão:

Os conceitos da razão pura (as idéias transcendentais) referem-se à unidade sintética incondicionada de todas as condições em geral. Por conseguinte, todas as idéias transcendentais podem reduzir-se a três classes (Klassen) das quais a primeira contém a unidade absoluta (incondicionada) do sujeito pensante, a segunda, a unidade absoluta da 
série das condições do fenômeno e a terceira, a unidade absoluta da condição de todos os objetos do pensamento em geral. (KANT 1987, B 391).

Temos assim que a forma lógica da relação determina suficientemente o conteúdo a ser pensado na idéia, o que indica, por sua vez, a espécie e a classe do raciocínio dialético - isto é, sob quais regras se dá o conflito da razão consigo mesma (enquanto entendimento puro e enquanto razão pura):

Os modos dos conceitos da razão pura... seguem o fio das categorias.

Com efeito, a razão nunca se refere diretamente a objetos, apenas aos conceitos que o entendimento tem desses objetos. (KANT 1987, B 392)

Portanto, a mesma função de síntese lógica de um dado intuitivo opera num plano em que se perde toda referência sensível. Daí a possibilidade de uma "derivação subjetiva" das idéias da razão a partir de conceitos do entendimento.

O conceito transcendental da razão é apenas o conceito da totalidade das condições relativamente a um condicionado dado. Como, porém, só o incondicionado possibilita a totalidade das condições e, reciprocamente, a totalidade das condições é sempre em si mesma incondicionada, um conceito puro da razão pode ser definido, em geral, como o conceito do incondicionado, na medida em que contém o fundamento da síntese do condicionado. (KANT 1987, B 379)

Que o conceito da razão em geral seja o do incondicionado se explica por uma questão lógica que pode parecer trivial, já que na própria síntese a priori do entendimento se encontram os elementos que permitem pensar, fora do alcance do entendimento, as condições de universalidade específicas da razão - ou seja, o conceito de uma totalidade incondicionada subjacente ao condicionado pelo conceito na experiência.

Não se pode propriamente dizer que esta idéia seja o conceito de um objeto, mas sim o da unidade completa desses conceitos, na medida em que esta unidade serve de regra ao entendimento. Semelhantes conceitos da razão não são extraídos da natureza; antes interrogamos a natureza segundo essas idéias e consideramos defeituoso o nosso conhecimento enquanto não lhes for adequado. (KANT 1987, B 674) 
Mostra-se aqui a potencialidade de significação que se encontra em todo e qualquer conceito do entendimento e que só se compreende adequadamente quando desvinculamos esse conceito do referente intuitivo. A indicação de que as idéias da razão acompanham em sua forma os conceitos do entendimento é explorada por Kant no sentido das "espécies de relações" que se podem representar no conceito de um incondicionado: "a síntese categórica num sujeito", "a síntese hipotética dos membros de uma série", "a síntese disjuntiva das partes num sistema" (KANT 1987, B 379). Essa conclusão baseada na asseveração anterior de uma origem lógica comum a conceitos de entendimento e idéias de razão permite a Kant descobrir um "sistema das idéias transcendentais" (objeto da 3a seção: KANT 1987, B 390 ss.) a partir do qual se engendram as diferentes maneiras de exposição da Dialética, as diferentes configurações do "conflito da razão consigo mesma": Paralogismo, Antinomia, Ideal - da razão pura. $^{7}$

Essas considerações de ordem lógico-transcendental justificam as divisões que balizam a exposição de Kant na "Dialética Transcendental" a partir das espécies de idéias da razão em três classes: "paralogismo transcendental", em que se infere a unidade incondicionada do sujeito a partir do "conceito transcendental do sujeito"; "antinomia da razão pura”, em que o conceito (entretanto contraditório) da unidade sintética incondicionada da série de condições me leva a concluir pela legitimidade dessa unidade; "ideal da razão pura", em que da totalidade de condições necessárias para "pensar objetos em geral” dados enquanto fenômenos eu concluo uma totalidade de todos os objetos, sejam eles dados a mim ou não - fenômenos e coisas em si (KANT 1987, B 398). Cada uma dessas classes de raciocínio envolve conceitos logicamente requeridos pela razão, mas transcendentes para o entendimento. Por isso essa dialética é natural ou estrutural, ao contrário dos sofismas artificiais e inteiramente contingentes que encontramos nos argumentos dos homens. E assim é forçoso reconhecer na "Dialética" uma inflexão expositiva necessária da "Analítica". Juntas, em rigorosa continuidade, elas respondem pelo corpo de uma Lógica transcendental como parte integrante de uma Crítica da razão pura. Esta não é uma doutrina, e a lógica que expõe é matéria de filosofia, não de manual: um manual de lógica não pode incluir nenhuma dialética, mas deve

doispontos, Curitiba, São Carlos, vol. 4, n. 1, p. 27-46, abril, 2007 
apenas expor uma doutrina que, para ser bem utilizada em filosofia, pressupõe uma crítica prévia. ${ }^{8}$

É em virtude das tentações dogmáticas oferecidas pelo estudo da lógica - prática material mais imediata do uso lógico do entendimento - que uma das tarefas da Dialética, tal como Kant a concebe, como crítica da aparência lógica, é detectar os dispositivos pelos quais essa aparência vicia a linguagem do metafísico. É que a promiscuidade entre uso canônico e uso orgânico da lógica pelo juízo redunda na utilização de uma linguagem aparentemente rigorosa que nos facultaria investigações nas mais rarefeitas regiões, como se o significado das palavras pudesse garantir de antemão o seu sentido. A Dialética assegura a legalidade do uso dos princípios lógicos do entendimento justamente ao mostrar a promiscuidade desse uso com o uso transcendental dos princípios da razão; a distinção entre os respectivos domínios do entendimento e da razão é aquilo que unicamente nos permite apontar para a ligação necessária entre eles (KANT 1987, B 675 - 76). Ora, as idéias da razão são antes princípios de unificação do que conteúdos de especulação, e entende-se porque, a propósito da definição da natureza ou da forma dessas idéias, Kant inflete a Dialética numa crítica das significações metafísicas tais como elas são expressadas em palavras, nas unidades de confecção do discurso filosófico. ${ }^{9}$

É o que vemos de maneira particularmente aguda no excurso inserido por Kant nessa mesma Dialética transcendental, intitulado "Das idéias em geral” (KANT 1987, B 368 - 77), um comentário simples e direto do uso filosófico do termo idéia na doutrina de Platão. O exercício filológico de Kant se refere principalmente ao texto da República. É curioso como, após uma breve introdução que distingue conceitos de idéias a partir de atos de percepção e de concepção, Kant parece sublinhar algo inteiramente alheio ao caráter epistemológico das idéias e à sua importância para o conhecimento. É que a discussão acerca do significado atribuído por Platão à palavra idéia chama a atenção para o fato de que o primeiro uso do termo na história da filosofia é vinculado a uma questão de ordem moral, que apenas subsidiariamente tem implicações epistemológicas: "Platão encontrava suas idéias principalmente em tudo o que é prático, isto é, que assenta na liberdade" (KANT 1987, B 371). Segundo Kant, esse achado do filósofo grego é tão mais valioso quando se lembra que

doispontos, Curitiba, São Carlos, vol. 4, n. 1, p. 27-46, abril, 2007 
toda tentativa de fundar a virtude na experiência "converte a virtude num fantasma equívoco, variável consoante o tempo" (KANT 1987, B 371). Os benefícios morais dessa advertência são imensos, pois permitem compreender que, se os modelos inteligíveis de virtude são inatingíveis, nem por isso tais concepções deixam de oferecer uma perspectiva mais promissora para o estabelecimento de regras morais de conduta, pois "todo juízo acerca de mérito ou demérito moral só é possível mediante essa idéia [da virtude]", idéia esta que não tem assim nada de quimérico (KANT 1987, B 372). Os fundamentos da moral só podem ser sólidos se forem pensados a partir da clivagem entre a instabilidade das coisas mundanas, sensíveis, e a fixidez das elaborações intelectuais da razão. $O$ hiato que separa a idéia da virtude de sua efetivação no mundo, longe de constituir uma objeção à sua viabilidade, oferece um motivo adicional para que nos empenhemos em tomá-la como um norte, não apenas de nossas ações individuais como também para a instituição de formas de "legislação e governo" (KANT 1987, B 373). ${ }^{10}$

Do ponto de vista de sua definição transcendental, o significado da palavra idéia tem uma referência epistemológica, ainda que negativa, como se vê mesmo no uso que dela faziam os gregos:

Platão servia-se da palavra idéia de tal modo que bem se vê que por ela entendia algo que não só nunca provém dos sentidos, mas até mesmo ultrapassa largamente os conceitos do entendimento de que Aristóteles se ocupou, na medida em que nunca na experiência se encontro algo que lhe fosse correspondente. (KANT, 1987, B 370).

Esse texto importante oferece algo raro e notável: a narrativa histórica de um descompasso transcendental. Os conceitos de Aristóteles são as categorias do entendimento, não provêm dos sentidos, mas aplicam-se a dados de intuição; as idéias de Platão tampouco provêm dos sentidos, mas ultrapassam as categorias na medida em que não há nada na experiência que corresponda ao que elas enunciam: referem-se a algo que está para além dos sentidos. As idéias de que fala Kant, enraizadas num solo comum ao das categorias, são entretanto incapazes de dizer o que quer que seja sobre as coisas às quais as categorias se aplicam. Platão entendia as suas idéias como "arquétipos das próprias coisas", "evocáveis por reminiscência”. Kant aceita que elas não se aplicam às coisas, mas, ao indicar um

doispontos, Curitiba, São Carlos, vol. 4, n. 1, p. 27-46, abril, 2007 
parentesco entre categorias e idéias, reverte a relação proposta por Platão. É que esse estar para lá das categorias do entendimento não é o índice de uma realidade "sublime", mas, o que talvez seja mais importante, o signo de uma característica própria da nossa faculdade racional:

Platão observou muito bem que a nossa faculdade de conhecimento sente uma necessidade muito mais alta que o soletrar de simples fenômenos pela unidade sintética para os poder ler como experiência, e que a nossa razão se eleva naturalmente a conhecimentos demasiado altos para que qualquer objeto dado pela experiência lhes possa corresponder, mas que, não obstante, têm a sua realidade e não são simples quimeras. (KANT 1987, B 370 - 71)

A razão não se contenta em "soletrar" os fenômenos, tal como fazem as categorias: quer algo mais. A imagem platônica de uma realidade para além do sensível é abandonada em prol de uma concepção mais sutil e mais difícil de ser posta em imagens: uma realidade intelectual a par de uma realidade sensível. Ou, para falarmos em jargão kantiano, o mundo sensível (do entendimento - categorias) a par do mundo inteligível (da razão - idéias). Os dois mundos de Platão são substituídos por dois princípio distintos de legalidades que instituem os seus respectivos domínios se referindo a uma só e mesma efetividade - aquela que interessa à razão humana como um todo. Entrevê-se aqui que as relações entre essas instâncias hão de ser, de alguma maneira, problemáticas. Pois se Platão se decidiu pela prioridade ontológica do inteligível diante do sensível, Kant, ao recusar o caráter 'essencial' das idéias, precisará repensar, nos três momentos da "Dialética transcendental", os termos da relação entre o sensível e o inteligível a partir de sua raiz comum nos princípios transcendentais da faculdade racional.

Mas tudo o que pretende a reviravolta kantiana em relação a Platão é colocar a questão em termos mais adequados, e de maneira alguma se trata de corrigir o espírito da especulação platônica na qual se encontra, para aquém dos equívocos da letra, algo verdadeiramente exemplar para o filósofo que estuda a razão pura ${ }^{11}$. O significado transcendental da palavra não esgota o seu sentido. $\mathrm{O}$ aporte moral das idéias platônicas indica um acerto: os juízos humanos do certo e do errado nas ações devem se pautar por um critério que esteja a resguardo das oscilações do 
mundo sensível. Kant acrescenta que a intuição de Platão também estava certa a respeito da "consideração da própria natureza" (KANT, 1987, B 374). Tudo na natureza, de plantas e animais à "própria estrutura do mundo" parece sugerir uma "ordenação" de sorte intelectual, como se as idéias dos particulares se orientassem por uma "determinação" do “entendimento supremo", "causa originária das coisas” (KANT, 1987, B 375). É como se a experiência, que é uma construção baseada em categorias do entendimento, terminasse por sugerir alguma coisa de interesse exclusivo da razão: um princípio de ordem separado da experiência e incognoscível pelos conceitos. Justifica-se assim a aspiração da razão, que quer algo mais que soletrar fenômenos precisamente porque esse exercício acaba por lhe sugerir uma instância a partir da qual o próprio soletrar é possível. A constituição de uma ordem da experiência pelas categorias do entendimento exige a idéia de um princípio de ordenação alheio ao entendimento. Por isso, pondera Kant,

Se pusermos de parte o exagero de expressão, o ímpeto espiritual do filósofo para se elevar da consideração da cópia que lhe oferece o físico da ordem do mundo até à ligação arquitetônica dessa ordem segundo fins, isto é, segundo idéias, é um esforço digno de respeito e merecedor de ser continuado. (KANT, 1987, B 375)

A significação correta da palavra idéia - "ligação arquitetônica da ordem segundo fins" - já se encontra em Platão, embora emaranhada em sentidos equívocos. O crítico, bom filósofo que é, não cria novas palavras, mas sabe buscá-las na tradição, em "línguas mortas”, para consolidar para elas um significado inequívoco, em meio à natural flutuação que elas possam ter na língua comum.

Apesar da grande riqueza das nossas línguas, muitas vezes o pensador vê-se em apuros para encontrar a expressão rigorosamente adequada ao seu conceito, sem a qual não pode fazer-se compreender bem, nem pelos outros nem por si mesmo. Forjar novas palavras é pretender legislar sobre as línguas, o que raramente é bem sucedido, e, antes de recorrermos a esse meio extremo, é aconselhável tentar encontrar esse conceito numa língua morta e erudita e, simultaneamente, a sua expressão adequada; e, se o antigo uso de tal expressão se tornou incerto, por descuido dos seus autores, é preferível consolidar o 
significado que lhe era próprio (embora persista a dúvida quanto ao sentido que, em rigor, se lhe atribuía) a prejudicar o nosso propósito, tornando-nos incompreensíveis (KANT, 1987, B 368 - 69).

A crítica comporta também uma arte, a invenção (no sentido técnico de seleção de palavras para a expressão de tópicos), que, posta a serviço da razão, renova a esperança de satisfazer o seu interesse especulativo em chave adequada, sem mais permitir que ela se deixe levar pelo impulso natural da especulação que turva a linguagem filosófica. Se a razão é por definição comunicativa, ou seja, se é possível ler e interpretar um texto de filosofia, por mais antigo que seja, então a consideração da linguagem da razão é uma tarefa central para o exame crítico da razão. Vale dizer que a uma crítica da razão parece indispensável o exercício da filologia. ${ }^{12}$

Mais importante para o argumento de Kant na Dialética é que a crítica histórico-filológica do uso do termo idéia em Platão permite indicar precisamente aquilo que distingue, em meio a suas afinidades, conceitos de entendimento e idéias de razão. Os "conceitos do entendimento" são "pensados a priori", independentemente de toda experiência; são essas formas puramente lógicas que "dão matéria ao raciocínio, e não há anteriormente a eles nenhum conceito a priori de objetos, a partir dos quais se possam concluir" (KANT, 1987, B 367). É claro assim que, no âmbito da "Dialética transcendental", a possibilidade de "raciocínios" é vinculada aos conceitos do entendimento que operam sínteses a priori com objetos de uma experiência possível, ou seja, que todos os raciocínios, baseados ou não em dados sensíveis, dependem da forma lógica desses conceitos. Por aí se vê como é difícil separá-los dos conceitos de razão. Com efeito, caberia perguntar: em que sentido Kant pode falar em conceitos especificamente racionais?

A denominação de conceito de razão já previamente indica que este conceito não se deverá confinar nos limites da experiência, porque se refere a um conhecimento do qual todo o conhecimento empírico é apenas uma parte (talvez a totalidade da experiência possível ou da sua síntese empírica). (KANT, 1987, B 367)

Reencontramos aqui o sentido depurado da idéia platônica. Conceitos de razão não se referem a objetos da experiência, mas à maneira de seu 
encadeamento - numa "totalidade", numa "síntese". Trata-se portanto de uma síntese de espécie mais elevada, pois é mais que uma "unidade", como aquela oferecida pelo entendimento, e parece referirse à experiência como ordem. Por mais que não se refiram a objetos da experiência, os conceitos de razão tomam a experiência como um objeto que transcende toda experiência possível para nós. Isso só é possível em vista da afinidade lógica entre conceitos de razão e conceitos de entendimento, que compartilham da mesma função de "objetividade" que faculta uma ampliação para além da experiência no sentido de abarcar o território em que se estabelecem os objetos empíricos passíveis de conhecimento. Esse pequeno deslocamento, entretanto fundamental, mostra qual a diferença específica entre entendimento e razão, enquanto poderes mentais: "Os conceitos da razão servem para conceber, assim como os do entendimento para entender (as percepções)" (KANT, 1987, B 367). A razão pensa mediante idéias; o entendimento conhece por meio de conceitos. Em virtude dessa conhecida distinção, o termo idéia perde o seu aporte transcendente, em que se descrevia um objeto supra-sensível, para adquirir relevo transcendental, pois agora idéia significa a espécie de representação em que um objeto supra-sensível é denominado sem ser conhecido. Daí a sua definição: "um conceito extraído de noções que transcende a possibilidade da experiência" (KANT, 1987, B 377), que não deixa de ser um triunfo do talento natural de discernir.

Compreende-se ademais a obstinação com que o filósofo crítico se apega aos termos legados pela tradição. É no interesse da manutenção desse arranjo delicado, sustentado nas relações sinuosas entre entendimento e razão, reconstituídas pela crítica, que Kant recomenda enfaticamente a todos

quanto têm a peito a filosofia (...) que tomem sob sua proteção a palavra idéia no seu significado primitivo, para que doravante não se confunda com as outras palavras pelas quais é hábito designar toda a espécie de representações, sem nenhuma ordem precisa e com grande prejuízo da ciência. Não nos faltam determinações convenientemente adequadas a toda espécie de representações sem haver necessidade de recorrer ao que é propriedade alheia (KANT, 1987, B 376).

doispontos, Curitiba, São Carlos, vol. 4, n. 1, p. 27-46, abril, 2007 
A existência de termos que designam de modo suficiente dadas representações e operações intelectuais mostra que não há desculpa para equivocidade quando temos a precisão ao alcance de nossas mãos. A Dialética, contraface crítica da lógica, não deixa de se pautar por critérios lógicos, inclusive quando se trata de prescrever, ainda que de maneira discreta, as regras do uso da linguagem filosófica. Palavras como idéia, que perduram através dos tempos, dão o testemunho de algo inerente ao uso da razão humana. Apesar de sua variação e imprecisão, elas dizem o que é a nossa razão, traem os anseios e declaram o interesse dessa faculdade. Por mais que não se refiram àquele objeto que denominam, o estudo das unidades lingüísticas do discurso metafísico é fundamental se quisermos compreender a natureza e os fundamentos dessa espécie de elaboração auto-referente que se engendra naturalmente a si mesma. O próprio Kant nos dá na Dialética o exemplo de precisão e rigor no uso das palavras, como quando pretende dar conta da referência necessária e inevitável a uma instância, por ora indeterminada, designando-a "suprasensível” (Übersinnliche), palavra que só pode ser artificial, por contraposição ao conhecimento sensível (Sinnliche). Aqui, a "variedade e riqueza das línguas" fornece ao filósofo o material de sua inventiva, processo ao qual se referia De Quincey no texto que nos serviu de ponto de partida. Essa variação de terminologia indica, por sua vez, o que se perde na sugestão de Platão: é a partir do sensível que se define, para nós, o transcendente enquanto supra-sensível, um termo que a rigor não significa nenhum objeto, mas que nem por isso deixa de ter sentido. Da crítica dessa espécie de sentido, desvinculado de toda significação particular, ocupa-se a Dialética transcendental.

\footnotetext{
${ }^{1}$ Ver a respeito PHILONENKO 1989., pp. 233 ss. e LEBRUN 1993, cap. 01.

2 Um raciocínio pode ser logicamente correto sem ter validade transcendental; é que a imprecisão semântica inscrita numa proposição qualquer escapa aos critérios lógicos de rigor e precisão na regulação dos raciocínios.

3 Um bom exemplo dessa diferença, entre muitos possíveis, é o difícil trecho em Que significa orientar-se no pensamento?, KANT, 1985, A $310-311$.

"Ver Lebrun, "Do erro à ilusão" (LEBRUN 1993b).
} 
${ }^{5}$ Seguimos a lição de Gérard Lebrun: "Não é o modelo do entendimento lógico que induz o entendimento cognoscente a ultrapassar os seus direitos? Não existe, tanto em um como no outro, em seu estado natural, a mesma confiança irrefletida em seu poder? Da aceitação do modelo lógico pela filosofia doutrinal passa-se portanto a uma crítica do caráter exemplar da lógica formal" (LEBRUN, 1993, p. 68).

${ }^{6}$ Ainda segundo Lebrun, "Com a dialética, a correspondência entre lógica pura (tábua das funções do juízo) e lógica transcendental (tábua das categorias) dá lugar a um questionamento dessa relação". LEBRUN, 1993, p. p. 67.

${ }^{7}$ Note-se de passagem que os termos do diagnóstico desse conflito indicam quão profundas serão suas implicações para o destino da metafisica, pois o que está em jogo é o estatuto científico das três disciplinas filosóficas que correspondem a cada uma das três idéias transcendentais: psychologia rationalis, cosmologia rationalis, theologia transcendentalis.

8 Consultar a respeito a introdução de Kant à sua Lógica, A 01 - A 10 (KANT, 1992). Que se compare esse texto àquele da introdução à Lógica transcendental (KANT, 1987, B 74 - B 82) em caso de dúvida quanto à diferença para a qual estamos apontando.

${ }^{9}$ Temos aqui algo como uma versão crítica da doutrina concebida por Lambert na década de 1770, “a constituição de uma língua científica, condição e meio de qualquer ciência”. Ver Manuel J. Carmo Ferreira, "Introdução” a Correspondência Lambert/Kant. KANT, 1988, p. 22. A inspiração de um projeto como esse é lockiana: ver Ensaio sobre o entendimento humano (LOCKE, 1978, p. 721).

10 Para que se tenha uma noção da importância dessa consideração para os desenvolvimentos ulteriores da filosofia de Kant, basta lembrar que alguns pilares do sistema da filosofia crítica são erguidos em elaborações conceituais derivadas dessa breve consideração - a moral, a filosofia da história, a doutrina do direito. Ver a respeito TERRA, 1995, parte I, cap. 01, "Doutrina das idéias".

11 Como explica Márcio Suzuki ao comentar o mesmo ponto que aqui nos interessa, “Ao tentar esse algo que (como havia corretamente suspeitado) se encontra além do alcance do conhecimento teórico, Platão, como que levado pela sublimidade do assunto, acabou usando uma linguagem tão 'elevada', tão 'retórica e obscura', que 'muitas vezes ele mesmo não entendeu'. Linguagem que, acredita Kant, pode todavia se prestar a uma 'interpretação mais branda e condizente com a natureza das coisas'. E é assim que o filósofo crítico se permite fazer uma exegese menos mística da palavra platônica idéia, observando que é possível entender um autor melhor até que ele mesmo" (SUZUKI 1988, pp. 29 - 30).

12 Filologia e filosofia sendo concebidas "numa osmose que modifica o sentido escolar de ambas as palavras" - para retomarmos a fórmula de Bento Prado Jr. em "Significar significa não ficar no signo" (PRADO JR. 2004, p. 09).

doispontos, Curitiba, São Carlos, vol. 4, n. 1, p. 27-46, abril, 2007 


\section{Referências bibliográficas}

KANT, I. 1974. Kritik der Urteilskraft. Herausg. Wwilhelm Weischedel. Frankfurt am Main: Suhrkamp.

1985. Que significa orientar-se no pensamento?. In: Textos seletos. Tradução de Floriano S. Fernandes. Petrópolis:Vozes.

1987. Crítica da razão pura. Tradução de Manuela Pinto dos Santos e Artur Fradique Morujão. 2a edição. Lisboa: Calouste-Gulbenkian.

1988. Correspondência Kant/Lambert. Organização e tradução de Manuel J. Carmo Ferreira. Lisboa: Presença.

1990. Kritik der reinen Vernunft. Herausg. Raymund Schmidt. Hamburg: Felix Meiner Verlag.

1992. Crítica do Juízo. Tradução de Antonio Marques e Valerio Rodehn. Lisboa: Casa da Moeda.

1992. Lógica. Tradução de Guido Antonio de Almeida. Rio de Janeiro: Tempo Brasileiro.

DE QUINCEY, T. 1987. Letters to a young man, "Letter V, On the English notices of Kant”. In. The collected works, Vol. X. Ed. D. Masson. Londres.

LEBRUN, G. 1993. Kant e o fim da metafísica. Tradução de Carlos Alberto Ribeiro de Moura. São Paulo: Martins Fontes.

1993b. "Do erro à ilusão". Tradução de Rubens Rodrigues Torres Filho. In: Sobre Kant. São Paulo: Iluminuras.

LOCKE, J. 1978. An essay concerning human understanding. Oxford: University Press.

PHILONENKO, A. 1989. L'oeuvre de Kant. 2 vols. Paris:Vrin.

PRADO JR., B. 2004. Prefácio à 2a edição de Rubens Rodrigues Torres Filho, Ensaios de filosofia ilustrada. São Paulo: Iluminuras.

SUZUKI, M. 1998. O gênio romântico. Crítica e história da filosofia em Friedrich Schlegel. São Paulo: Iluminuras. 
TERRA, R. R. 1995. A política tensa. Idéia e realidade na filosofia da história de Kant. São Paulo: Iluminuras.

TORRES FILHO, R. R. 2004. “A virtus dormitiva de Kant”. In: Ensaios de filosofia ilustrada. 2a edição. São Paulo: Iluminuras. 